Effort has been made to deliver water in the laboratories as little changed as possible from that at the pier head; all the pipes and taps are of celluloid ; the pump, electrically driven, is stoneware lined. The concrete tank is as small as possible, its water being renewed two or three times in the 24 hours. This arrangement has proved eminently successful. Corals, some alcyonarians, echinoderms and fish seem able to live in the tanks indefinitely; the huge scarlet nudibranch, Hexabranchus sanguineus, Chromodoris quadricolor, the gaily coloured Balistes aculeatus, the great anemone Actinia quadricolor and its active hunter, the bright little fish Amphiprion bicinctus, are among the species which have been kept alive for many weeks.

The launch is open, 35 feet long, with 30 H.P. paraffin engine and auxiliary sail as a safeguard. It is fitted with a winch for hauling nets, circulating sea-water pump, hand-winch for water bottles, and a Lucas sounding machine. Of the two sailing boats, the larger brings freshwater from the Oilfields' piers and the smaller is used for fishing. Dredges and trawls of the usual kinds are provided, together with the simpler oceanographical apparatus.

Microscopes and all ordinary glassware and reagents are provided for biological and physiological work and for chemical researches. The library is at present small, but it contains the reports of the principal tropical expeditions, etc., and a series of periodicals.

Applications for accommodation should be made to the Director and should include approximate dates of arrival and departure, the work it is intended to do, and any special arrangements desired. On arrival in Egypt, a telegram should be sent (address Biological Station, Hurghada) on receipt of which the Director will arrange passages from Suez. Living accommodation at the station consists of three small bungalows, simply but comfortably furnished, and a cook is provided.

${ }^{1}$ Nature, 124, 991, Dec. 27, 1929.

\title{
Solid Products of Carbonisation of Coal
}

$\mathrm{D}^{2}$ URING the last fifteen years, a flood of publications on the properties of cokes has appeared, much of it scientifically interesting, but uncorrelated with industrial practice. When large-scale processes, for example, the blast furnace, are in question, this is understandable, for conditions are complex and often elude experimental control. Although such difficulties are less evident with small-scale operations, such as the open and closed domestic fires, there is no large volume of published careful experimental work about them. Nevertheless, these publications have shown that the behaviour of a fuel in an open grate can be related to its properties ascertainable in the laboratory. Now a brochure issued by the South Metropolitan Gas Co.* reveals that its chemical staff has been studying this subject for a decade past. It is a comprehensive monograph disclosing a considerable body of work which is, in a large measure, parallel in scope and conclusions with previously published results. The experimental methods used, some of which are novel, will interest students of coke.

Converging evidence detailed points to $700^{\circ}$ as the critical temperature dividing 'high' and 'low' temperature carbonisation. The South Metropolitan Gas Co. carries on both types of manufacture, and the experimental work recorded covers both. As few

* South Metropolitan Gas Company : Chemical Department. The Solid Products of the Carbonisation of Coal. Pp. $123+4$ plates. (London: South Metropolitan Gas Co., 1934.) 38. $6 \dot{d}$. net. concerns are in this position, the experience recorded is of special importance.

Mention may be made of one test of general interest. A library room was heated on alternate days throughout winter with coal and "MetroCoalite" in an ordinary grate under the control of the normal occupant of the room. Careful measurements showed that the weight of coal used was the greater in the proportion of $1 \cdot 37$ to 1 . This higher efficiency compensates for the greater cost of the "Metro-Coalite", and is a necessary consequence of its lower proportion of volatile matter. The fuel with the higher carbon content has the advantage as a source of radiation, and from this point of view, volatile matter in coal is not merely an objectionable source of smoke, but rather an expensive luxury.

The advantage of high carbon content is greatest with high temperature cokes, and in suitably designed appliances this advantage is being increasingly realised. The South Metropolitan Gas Co. was active in developing grates designed to burn cokes, and experimental work in the subject is recorded. A recent estimate places the number of coke-burning grates sold last year at 69,000 . Such a measure of popularity is to be explained by the fact that high efficiency is combined with cheapness of fuel and economy of labour. As the fuel is smokeless, the popularisation of such appliances is an important contribution to public hygiene.

H.J.H.

\section{Psychological Needs in Animals}

$\mathrm{P}^{\mathrm{P}}$ ROF. DAVID KATZ (Rostock) in an address on "Some Problems of the Psychology of Needs" to Section J (Psychology) of the British Association at Aberdeen pointed out that the study of needs seems to be one of the most important tasks of modern psychology. A general view of the whole range of needs (vital, social, artistic and religious) must first be undertaken. Once this has been achieved, two other tasks remain to be investigated: (1) the objects which serve the satisfaction of needs, (2) the methods by which the needs are satisfied. Different needs all reveal the same fundamental laws, but no other need offers, from the point of view of content and method, such a profitable object of investigation as the satisfaction of hunger.

The laws of the satisfaction of hunger reveal the fundamental dynamic relations of all needs, how they are influenced by inner and outer factors and by historical factors which are partly rational and partly irrational. The concept of need may in some fields be more helpful than the concept of instinct, 
particularly in such cases where we meet an amazing plasticity in the adaptation of the behaviour to unusual conditions.

By means of a film, Prof. Katz showed the results of investigations on the dissolution of the family in hens. Many factors influence the process of the dissolution of the family. In general, the family lasts so long as a certain physiological state of the hen exists. But in addition to this physiological state, there exist psychological factors which influence the duration of the family group. The hen keeps the chicks the longer the fewer their number, and this irrespective of their size. The dissolution of the family takes place in an active way, the hen actually driving away her chicks. The maternal drive, however, seems to revive again in the presence of danger. The chicks when driven away by the hen keep together for a certain time, forming a gynopædium.

In a second film, Prof. Katz showed the results of interesting experiments carried out on the localisation of sounds by dogs. A dog is trained to run to a small screen behind which a noise, of about half a second's duration, is produced by means of an electric buzzer. Several screens are then placed in a row, the buzzer is sounded, and the dog has to locate the noise by running directly to the appropriate screen. The performances of the dog in locating the noises are amazing. The dog is even successful in distinguishing between two screens when the two are not more than $25 \mathrm{~cm}$. apart, although its own distance from them both at the start is about $5 \mathrm{~m}$. Scarcely any error appears when the dog sits in the centre of a circle of about $10 \mathrm{~m}$. diameter, and 64 screens are distributed at equal distances on the circumference of the circle.

Dr. B. P. Wiesner showed two films demonstrating maternal behaviour in the rat. The studies on these subjects support the point of view of purposive psychology to a considerable extent, but also show that the activities of the animals are not regulated by the achievement of the 'purpose' ; many activities are pursued well beyond this point and apparently without relation to field situation or to 'necessity' (Beduerfnis). The experiments were extended to a study of the physiological factors underlying maternal behaviour. Observations suggest that the exteroceptors normally engaged in the performance of maternal activities are not necessary for their occurrence but only for their direction. Endocrine factors originating in the pituitary gland (anterior lobe) are probably at the basis of maternal activities. It is possible to produce maternal behaviour in virgin rats by extracts from this gland.

\section{Inversion of $d$-Camphor}

$\mathrm{I}^{\mathrm{N}}$ recent years, Messrs. Asahina and Ishidate, of the University of Tokyo, have been engaged in the investigation of derivatives of camphor and have collected some useful data bearing upon the constitution of these compounds. The results are published in the Berichte der deutschen chemischen Gesellschaft.

Although the camphor molecule contains two dissimilar asymmetric carbon atoms, it can, by reason of certain limitations imposed upon it by ringclosure, give rise only to two optical isomerides, namely, $d$-camphor and $l$-camphor, both of which are known and are designated as 2-keto-camphane and 6-keto-camphane respectively. Similarly, 3- and 5-keto-camphanes form another optical pair, $l$-epicamphor and $d$-epi-camphor. Now it has been known since 1914 that each camphor can be transformed into the epi-camphor of opposite sign, but in the August issue of the Berichte, Asahina and Ishidate explain how they have been able to effect the conversion of $d$-camphor into $d$-epi-camphor and the latter into $l$-camphor, thus inverting the molecular configura. tion, but in claiming to be the discoverers of $d$-epicamphor, they have obviously overlooked the preparation of this substance by Furness and W. H. Perkin in 1914.

The complete cycle of changes as described by the Japanese authors in the inversion of $d$-camphor involves the preparation of 2.5-diketo-camphane from campherol, a product of animal metabolism, but, since Bredt and Goeb prepared the same diketone in 1920 by the oxidation of bornyl acetate, derived from $d$-camphor, to acetoxy-camphor and further oxidation of the hydrolysed product, it is obvious that life-processes are not an essential feature of the transformation.

Campherol was characterised as a mixture of at least two and probably four hydroxy-camphors, from which 5-hydroxy-camphor was isolated in the pure condition. On oxidation with chromic acid, this gave 2-5-diketo-camphane, a tautomeric mixture, of which the keto-modification could be stabilised by repeated recrystallisation from acetic acid. Hydrogen cyanide attaches itself exclusively to the 5 -keto group of this compound, whereby a now 'asymmetric centre' is developed so that two stereoisomeric hydroxyacids are formed after hydrolysis. Resolution of this mixture is, however, unnecessary, because after reduction of the 2-keto group to methylene, the hydroxyacid group is reoxidised to carbonyl. The resulting product is 5-keto-camphane (d-epi-camphor), the configuration of the original asymmetric atoms remaining unaffected. The next step is to oxidise $d$-epi-camphor with selenium dioxide to 5-6-diketo-camphane or $d$-camphorquinone (the optical isomeride of ordinary $l$-camphorquinone from $d$-camphor). Reduction of this compound gives a mixture of 5-hydroxy-6-keto-camphane and 6hydroxy-5-keto-camphane, the methyl ethers of which can be separated. Further reduction of the former with sodium amalgam gives $l$-camphor (6-keto-camphane), thus completing the inversion.

\section{University and Educational Intelligence}

London.--Dr. L. J. Witts, since 1929 assistant physician to Guy's Hospital, has been appointed professor of medicine (St. Bartholomew's Hospital Medical College); Prof. Geoffrey Hadfield, professor of pathology in the University of Bristol, has been appointed professor of pathology (St. Bartholomew's Hospital Medical College). The following appointments have been made in the British Postgraduate Medical School : Mr. A. A. Miles, demonstrator in the Department of Pathology at the University of Cambridge, to be reader in bacteriology; Dr. R. S. Aitken, first assistant to the Medical Unit at the London Hospital, to be reader in medicine ; Dr. J. C. Moir, assistant to the Obstetric Unit at University College Hospital, to be reader in obstetries and gynæcology ; Dr. Earl J. King, assistant professor of medical research and director of the Sub-Department 